\title{
Asking the 'Cyber' question: Whose use of what information and communication technology creates which changes for whom?
}

*Kristjan Kikerpill, University of Tartu

\section{Purpose}

The purpose of this brief article is to trace and explain the ubiquitous yet elusive term 'cyber', which is omnipresent in media stories, international policy discussions, law enforcement efforts and internet studies. The persistently elusive nature of the term has evoked discussions on the usefulness of the term in describing and discussing modern human-computer(-human) interactions. This article clarifies the contents of the term and offers a clear approach to usage moving forward.

\section{Design/methodology/approach}

This is a general review article that traces the history of the elusive term 'cyber' by putting the development story together from available sources on early cybernetics and the subsequent rise of information technology, personal computers and the internet.

\section{Findings}

The term 'cyber' presents best through the conceptual 'Cyber' question, i.e. "Whose use of what information and communication technology creates which changes for whom?". The modern use of 'cyber' shares a history with 'cybernetics', but relates more narrowly to modern information and communication technologies through a specific re-emergence of the prefix from science fiction literature to international policy and academia to everyday usage.

\section{Originality}

The article focusses on the term and concept 'cyber', i.e. investigating its origins, emergence 
and the related terminological confusion. By posing the inquiry and explanation in the form of a guiding 'Cyber' question, the article provides a solid basis for the future use and understanding of the term 'cyber' as evoked in academic, policy or public discussions.

\section{Introduction}

'It sounds like you're trying to be cool, but you're not,' a student clarified the reason for changing the name of their high school security club from Cybersecurity Club to Computer Security Club in 2013 (Perlroth). (Un)fortunately, academic discussions do not enjoy the luxury of altering terminology based on 'cool', or lack thereof, alone. Nevertheless, the student's brief reply accurately sets the tone for anyone embarking on a discussion involving the use of the term 'cyber' beyond its buzzword capacity. Hence, numerous investigations into the term's origins and current meaning have been previously undertaken (Newitz, 2013; Wolff, 2016; Bay, 2016).

Given that no use of language is semantically neutral, each iteration of a concept inevitably also alters our understanding of it (Gerring, 1999). Therefore, 'cyber' could be considered to have joined the company of 'culture' (Birukou et al., 2013) and 'justice' (Holsinger and Sexton, 2017), i.e. terms which are widely used but evade interpretational uniformity due to their conceptual expansiveness. Combined with uncertainty, this expansiveness can lead us to think of 'cyber' as a floating signifier (Mehlmann, 1972; Laclau, 1994), i.e. a term without a fixed meaning. Futter (2018) has suggested that it might be time to retire the term 'cyber', as it entails confusion instead of clarity, ultimately obstructing both academic and policy-related discussions. The presented concern undoubtedly carries weight and must be addressed, although the offered solution is certainly unusual (Futter, 2018, p. 213). 
Furthermore, how exactly one might surgically remove 'cyber', or get everyone to agree to avoid using the term in academic and policy discussions is left unclear.

While there exist excellent accounts of the emergence and wide-spread adoption of information technologies (Cortada, 2012) as well as the struggles and developments in the cyber domain (Tikk-Ringas, 2015), the term 'cyber' itself has remained elusive. In this article, I contend that cyber studies as such comprise the debates, analysis and management of the substance of the 'cyber' question: "Whose use of what information and communications technology creates which changes for whom?”.

\section{From Ancient Steersmen to Norbert Wiener's 'Cybernetics'}

For the English language, the foundational work on cybernetics by Norbert Wiener (1948) is the point of departure towards the modern result of 'cyber'. Albeit with a different meaning attached to the term, 'cybernetics' had counterparts in other languages that pre-dated Wiener's use, e.g. cybernetiqué was used by Ampere more than a century before Wiener (see Scott, 2018) in French and kibernetiki by Trentowski in Polish to signify 'governance' (Novikov, 2016). In his inquiry, Norbert Wiener was first looking for a Greek word signifying 'messenger' and came up with angelos, or angel, 'the messenger of God' which was preempted (Wiener, 1956; Bay, 2016). Wiener then searched for a suitable word from the field of control and came up with 'steersman', kubernetes. Johnson (1998) elaborates on cybernetiqué and cybernetics, also stating that these and related words in other languages are rooted in the ancient Greek kybernetikos, meaning 'steering'. Both the 'skill in navigation' (aretes kybernetikes) in Plato's Alcibiades I or the 'art of governance' (kybernetike tekhne) as preferred by Aristotle (Johnson, 1998), have a great emphasis on activity. Wiener's 'cybernetics' did not describe objects' static states of being either, but the exchanges or the potential for exchanges that would entail adjustments, i.e. control, in self-regulating systems as these interacted with 
their environments. Alongside 'cybernetics', the Ancient Greek roots kybernetes or kybernetike are also recognised as having provided other frequently used terms to our vocabulary, most notably 'governance' and 'governor'. In a technical context, James Watt used the term 'governor' in 1789 to describe the flyball feedback apparatus that controlled the speed of his steam engine (Conway and Siegelman, 2006). The account provided by Conway and Siegelman (215) suggests that at the time of coining the term, Wiener had not been aware of Ampere's use of cybernetiqué. Instead, Wiener traced the etymology of Watt's 'governor', which ultimately led him to kybernetes (Bechtel, 2005, p. 48). In a way then, Wiener's (1948) later choice of the word was both an homage to the steersmen of ancient times as well as the practical devices emerging in the industrial age that incorporated notions of feedback and control.

The concept of cybernetics, and the potential applications of cybernetics thinking, spread to disciplines outside mathematics, starting from the Macy Foundation Conferences on Cybernetics that took place from 1948 to 1953 (Kline, 2015). Anthropology, neuroscience, physiology, physics and engineering were all influences for what 'cybernetics' came to signify shortly after its emergence (Kline, 2015, pp. 2-5). In such a diverse environment of intellectual exchange, 'cybernetics' was bound to become a floating signifier.

\section{Declining Cybernetics, Rising Information Technology}

It was the spread and inclusion of cybernetics thinking into other disciplines that brought with it a diminishing image for cybernetics itself. As Kline (2015, p. 179) accounts, "the cybernetics moment came to an end $[\ldots]$ not with the death of cybernetics, but with its decline, revival, and reinvention". Cybernetics inspired research into humans as machines, e.g. experimental psychology research into stimulus response, humans aided or enhanced by machines, e.g. bionics, and machines as humans, e.g. artificial intelligence. Additionally, cybernetics' stock 
dropped in the West once the Soviet Union heralded cybernetics as their new scientific language (Gerovitch, 2009), taking a much broader approach compared to their Western counterparts. Hence, almost from the inception of the concept itself, something 'cyber' became the source of political contention. Substantively, the decline of cybernetics came from its fragmentation into different disciplines and surmounting Cold War tensions (Kline, 2015), but also because the broad concept of cybernetics lent a hand to fantastic ideas suitable for science fiction rather than real science of the time (p. 183).

In the 1960s, the ongoing space race pushed researchers to look for new horizons and led them to thinking about the survival of a man in unknown environments. The work of Clynes and Kline (1960, p. 26) suggested that “scientific advances of the future may [...] permit man's existence in environments which differ radically from those provided by nature as we know it". The discussion was about the possibility of altering man himself, by further studying homeostatic functioning and its cybernetic aspects to allow humans to change their modus vivendi with the help of biochemical, physiological and electronic modifications. 'Cyborg' was the operating term coined by Clynes and Kline (1960), derived from the combination of cybernetics and organism. At the time, there was certainly a fantastical element to these and similar ideas, but some of them ended up as our reality. For example, advances in artificial intelligence, bionics and cyborgs was something that caused Norbert Wiener (1964) great concern before his death, i.e. the question of whether a creator ought to build a machine he or she could not understand, or control. This concern about the potential applications of AI is still shared by many leading researchers in the area today (Wolchover, 2015). Nevertheless, the idea of a cyborg shows once more how 'cyber' was evoked when humans were contemplating the creation of impacts on other humans through the use of modern technology (see American Chemical Society, 2020). 
The notion that cybernetics itself began to be shunned did not decrease the importance of cybernetics thinking both as absorbed into a multitude of disciplines and inspiring others. Reliance on machines and information processing in enhancing aspects of business management, i.e. applications of information technology (Kline, 2015, pp. 202-228), arose whilst cybernetics had not faded yet, but the notion of the digital computer was certainly on the rise in terms of significance and potential for overtaking cybernetics. This is epitomised in a 1965 Time magazine piece referring to cybernetics as the 'science of computers' (Time, 1965), i.e. the connection that would still spur confusion five decades later seemed to be in place from the very beginning. When Douglas Engelbert first showed the prototype of the modern computer in 1964, both with a mouse and a graphical user interface, the digital computer's journey from being a specialised technology in the service of scientists and researchers to being more accessible to the general public had begun (Zimmerman, 2017). We should also acknowledge how the use of the term 'technology' had changed (Schatzberg, 2006) and the way the term 'information technology' developed and supplanted cybernetics (Kline, 2006). The rise of the personal computer in the 1970s and its coming of age in the early 1980s, accompanied by an increasing availability of options for connections between machines and, thus, the humans using them, was only a step away from the social transformations we take for granted today. For instance, the cover of the Time magazine (Time, January 3, 1982) departed from its tradition of announcing a Man of the Year, declaring the computer as its Machine of the Year instead. The time between the personal computer becoming accessible and the World Wide Web still to come, allowed for the continued flow of ideas that seemed concurrently utopian and tangible. The emergence of the personal computer certainly spurred concerns among the general population (Lafrance, 2015) well before widespread access to the Internet was available. Growing concerns about computers and their potential applications were present before anything was specifically dubbed 'cyber'. From ideological strife regarding choice in 
scientific language and thinking, and enhancing humans themselves with the help of novel technology, to making available a machine that would completely transform modern society, 'cyber' was always present in these developments even if at times implicitly.

\section{From 'Cyberpunks' to Modern 'Cyber'}

Cyberpunk literature that grew out of the New Wave science fiction literature of the 1960s and 1970s, gave us the next important step in the 'cyber' story, when Bruce Bethke's 1980 work 'Cyberpunk', published three years later (Bethke, 1983), provided us the prefix that we use today. Bethke (2019) stated that coining the term was deliberate and comprised of 'cyber' as representing high technology and 'punk' for misdirected youth. Perhaps unsurprisingly, the combination of high technology and unconventionally thinking youths also matches the description of those who founded today's technology giants, e.g. Microsoft, Apple, Facebook and Google.

The other, better known usage of the prefix appeared when Gibson used 'cyberspace' in his novelette Burning Chrome ([1982] 2003). It must be clarified that the term 'cyberspace', prior to its description as a 'digital hallucination', was summoned into existence by Danish artist Susanne Ussing and architect Carsten Hoff in 1968 (Lillemose and Kryger, 2015) but in their use had nothing to do with technology. However, it is through Gibson's use of the term in his award-winning novel Neuromancer (1984) that 'cyberspace', in colloquial usage, later came to represent anything and everything about connected computers and the people using (or abusing) them. The history of the term 'cyberspace', then, is in some ways similar to the situation that occurred with Wiener, Ampere and 'cybernetics'.

Problems related to and emanating from connected computers, including issues related to human, software and hardware vulnerabilities, have been present since the establishment of such connections in the 1960s (Warner, 2012). The creation of the WorldWideWeb, the release 
of Mosaic and the related commercialisation efforts of the first half of the 1990s were pivotal in launching both the idea as well as the seemingly endless potential of the Internet to the masses (Naughton, 2016). However, this meant that the problems and vulnerabilities that were present in computers three decades earlier were unleashed alongside their potential. Even if the development of issues is gradual, emerging problems are often not dealt with prior to so-called watershed moments and for 'cyber', this moment seems to have been the Eligible Receiver cyberwar exercise conducted in June 1997 (Kaplan, 2017).

On October 13, 1997, the US President's Commission on Critical Infrastructure Protection (President's Commission, 1997) released its report that, among other things, imprinted the word 'cyber' onto national and international policy discussions which were related to the 'new threat' emanating from connected computer systems. Kaplan (2017) gives an account of how 'cyber' ended up as the word describing these new threats, stating that it was a US Justice Department lawyer who advocated adopting 'cyber' as the term of reference. Others had opposed it, because the term sounded too fantastical, but 'once uttered, the word snugly fit. From that point on, the group-and others who studied the issue-would speak of "cybercrime," "cyber security," "cyber war."' (45). Given how influential the US was, and is, in matters of cybersecurity (Cavelty, 2014), the 'cyber' issues that built momentum in the 1980s came of age during the 1990s. Similar issues and developments were concurrently under discussion in other countries (see e.g. Tabansky and Israel, 2015; Schallbruch and Skierka, 2018). In addition to a plethora of policy developments and concerns (Tikk-Ringas, 2015; Rid, 2016, p. 292), the proliferation of the term 'cyber' from the 1990s onward can be illustrated in another way. Google Ngram results for 'cyber' from 1948 to 2007 (Google, 2019) show that the relative usage of the term 'cyber' exploded starting in 1995, going from $0,000020 \%$ in that year to $0,0001305 \%$ in 2007 . Hence, 'cyber' was firmly planted into colloquial usage earlier and only later embedded into policy discussions, yet this time for good. "What is proper and 
what is not proper" behaviour in cyberspace (Henriksen, 2019, 1) has become one of the most important policy questions of our time. Within these policy discussions, 'cyber' has gained a solid, although as yet conflicted, foothold as a term. However, cyber studies concern more than just international and domestic policy. Similar to the interdisciplinary initial discussions of cybernetics at the Macy Conferences, the current breadth of cyber studies includes, at minimum, legal and criminological studies (cybercrime), computer science, social and behavioural sciences (cybersecurity) as well as psychology (cyberbullying). Of course, there are numerous other areas of inquiry where the prefix 'cyber' does not occur, but which also seek answers to 'cyber' questions, e.g. business and commerce as well as communication and culture studies.

\section{Settling the Ongoing 'Cyber' Confusion}

In the context of 'cyber' discussions, the terms 'cybercrime' and 'cybersecurity' can be used to illustrate the concept of a floating signifier. Floating signifiers are terms not fixed to a specific meaning (Mehlmann, 1972), because either an overdetermination or an underdetermination of signifieds, i.e. what the term points to, prevents us from fully fixing it (Laclau, 1994). These signifiers see their meaning shift across contexts and perspectives (MacKillop, 2018). For instance, the competing signifiers for what the term cybercrime ought to signify are 'electronic crime,' 'computer crime,' 'computer-related crime,' 'hi-tech crime,' ‘technology-enabled crime', 'e-crime' or 'cyberspace crime' (Chang, 2012; Sarre et al. 2018).

Furthermore, the issues are not restricted to signifiers but also extend to the signified. For example, McGuire and Dowling (2013) distinguish between cyber-enabled offences, e.g. fraud, and cyber-dependant ones, e.g. spreading malware. Grabosky (2007) suggests a different three-way distinction, where computers are used either as the tools for crime, incidental to the offence, or as targets of crime. Developments and debates concerning what 'cybercrime', or its 
competing signifiers, communicate as their attached meaning have been ongoing since the early 2000s (Grabosky 2001; Capeller, 2001; Maimon and Louderbeck, 2019). Nevertheless, criminal convictions still solely depend on the applicable law, not academic deliberations (Kikerpill and Siibak, 2019).

However, most 'cyber'-related terminological developments are not aided by the presence of such cut-off points, e.g. the term 'cybersecurity', the second notable and frequently featured signifier in 'cyber' terminology discussions (Bay, 2016; Kasper and Antonov, 2019). Additionally, 'cyber' itself has been used as an abbreviation for the term 'cybersecurity' (Nolan et al., 2019). Given the confusion surrounding 'cyber' in security studies, Futter (2018, p. 211) suggested that 'cybersecurity' could be deconstructed into its constitutive components of information security, network security and computer security. Thus, 'cybersecurity' has numerous competing signifiers all vying for roughly the same signified. While information security and 'cybersecurity' have indeed been found to exhibit substantial overlap, 'cybersecurity' goes beyond traditional information security by including the protection of persons as a goal (von Solms and van Niekerk, 2013). Alternatively, there are actors who make it very clear that protecting information is the goal (Giles, 2012), which entails specific restrictions to people subject to such an approach. In cases where 'cybersecurity' is not evoked, authors point to a need for more attention to the so-called soft issues in information security, e.g. humans and policies (Futter, 2018, 211; Lundgren and Möller, 2019). When perpetrators are successful in exploiting the weaknesses present in an organisation's systems or its human factor, 'cyber-harms' are bound to occur (Agrafiotis et al., 2018).

Considering the wealth of use cases for 'cyber' (Coe, 2015), it seems near impossible to try and remove it from our academic and policy vocabularies at this point. However, it is possible to bring more clarity to the future use of the 'cyber' signifier by relying on its emergence. If the story and meaning of 'cyber' ultimately addresses how humans use 
information and communications technologies to create change, cyber studies must provide the wisdom for managing such affairs. The former must be fixed and clarified to strengthen and improve discussions of the latter - both to mitigate the 'cyber' negatives and, perhaps more importantly, encourage the 'cyber' positives. The inevitably broad range of specifying questions, which come after the 'cyber' question has been submitted, form the core of academic and policy discussions where humans and modern technology appear together.

In conclusion, some form of 'cyber-' and questions relating to how humans use technology to create impacts on other humans or themselves have never been too far from one another. If anything, using 'cyber' to refer to changes created in connection with information and communication technology and, more specifically, the human use of the latter resembles a return path to the original. The choices in managing the aforementioned changes form the core of modern cyber studies in its broadest sense, thus also informing how we as individuals choose to use information and communication technologies and the types of changes such use creates for ourselves and others. Ultimately, the goal is not to substitute existing vocabulary with 'cyber' additions anywhere that humans and information technology interact to create change, but to cease shunning the term due to lack of understanding.

\section{REFERENCES}

Agrafiotis, I., Nurse J. R. C, Goldsmith M., Creese S. and Upton D. (2018), “A Taxonomy of Cyber-harms: Defining the Impacts of Cyber-attacks and Understanding How They Propagate", Journal of Cybersecurity, Vol. 4 No 1, pp. 1-15. https://doi.org/10.1093/cybsec/tyy006

American Chemical Society. (2020), “'Cyborg' Technology Could Enable New Diagnostics, Mergers of Humans and AI", available at: https://phys.org/news/2020-08-cyborg-technologyenable-diagnostics-merger.html (accessed 23 February 2021)

Bay, M. (2016), "What is Cybersecurity?". French Journal of Media Research, Vol. 6, available at: http://frenchjournalformediaresearch.com/lodel-1.0/main/index.php?id=988 (accessed 23 February 2021)

Bechtel, W. (2005), Discovering Cell Mechanisms: The Creation of Modern Cell Biology. Cambridge: Cambridge University Press. 
Bethke, B. (1983), “Cyberpunk”, Amazing Science Fiction Stories, Vol. 57 No. 4.

Bethke, B. (2019), Cyberpunk: A Short Story, available at: http://www.infinityplus.co.uk/stories/cpunk.htm (accessed 23 February 2021)

Birukou, A., Blanzieri E., Giorgini P. and Giunchiglia F. (2013), "A Formal Definition of Culture", in Sycara K., Gelfand M. \& Abbe A. (Ed.s), Models for Intercultural Collaboration and Negotiation. Advances in Group Decision and Negotiation, Dordrecht: Springer, pp. 1-26.

Capeller, W. (2001), "Not Such a Neat Net: Some Comments on Virtual Criminality", Social \& Legal Studies, Vol. 10 No. 2, pp. 229-242. https://doi.org/10.1177/a017404

Cavelty, M. D. (2014), Cybersecurity in Switzerland. Springer International Publishing.

Chang, L. Y. C. (2012), Cybercrime in the Greater China Region: Regulatory responses and crime prevention across the Taiwan Strait. Cheltenham, UK: Edward Elgar Publishing.

Clynes, M. E. and Kline N. S. (1960), “Cyborgs and Space”, Astronautics, September 26-27, pp. 74-76.

Coe, T. (2015), "Where Does the Word Cyber Come From?" OUPblog, March 28, available at: https://blog.oup.com/2015/03/cyber-word-origins/ (accessed 23 February 2021)

Cortada, J. W. (2012), The Digital Flood: The Diffusion of Information Technology Across the U.S., Europe, and Asia. New York: OUP.

Conway, F. and Siegelman J. (2006), Dark Hero of the Information Age: In Search of Norbert Wiener, The Father of Cybernetics. New York: Basic Books.

Futter, A. (2018), “'Cyber' Semantics: Why We Should Retire the Latest Buzzword in Security Studies”, Journal of Cyber Policy, Vol. 3 No. 2, pp. 201-216. https://doi.org/10.1080/23738871.2018.1514417

Gerovitch, S. (2009), "The Cybernetics Scare and the Origins of the Internet", Baltic Worlds, Vol. 2.

Gerring, J. (1999), "What Makes a Concept Good? A Criterial Framework for Understanding Concept Formation in the Social Sciences", Polity, Vol. 31 No. 3, pp. 357-393.

Gibson, W. (1984), Neuromancer. New York: ACE.

Gibson, W. (1982) 2003, Burning Chrome. Reprint, New York: HarperCollins.

Giles, K. (2012), "Russia's Public Stance on Cyberspace Issues", in 4th International Conference on Cyber Conflict (CYCON 2012), Tallinn, Estonia, pp. 1-13.

Google. (2019), ‘cyber' 1948-2007, Google Ngram Viewer, available at: https://books.google.com/ngrams/graph?content=cyber\&year_start=1948\&year_end=2007\&c orpus $=15 \&$ smoothing $=3 \&$ share $=\&$ direct_url $=\mathrm{t} 1 \% 3 \mathrm{~B} \% 2 \mathrm{Ccyber} \% 3 \mathrm{~B} \% 2 \mathrm{Cc} 0 \# \mathrm{t} 1 \% 3 \mathrm{~B} \% 2 \mathrm{Ccyb}$ er\%3B\%2Cc0 (accessed 23 February 2021)

Grabosky, P. (2001), "Virtual Criminality: Old Wine in New Bottles?", Social \& Legal Studies, Vol. 10 No. 2, pp. 243-249. https://doi.org/10.1177/a017405

Grabosky, P. (2007), Electronic Crime. New Jersey: Prentice Hall. 
Henriksen, A. (2019), "The End of the Road for the UN GGE Process: The Future Regulation of Cyberspace", Journal of Cybersecurity, Vol. 5 No. 1. https://doi.org/10.1093/cybsec/tyy009

Holsinger, K., and Sexton L. (2017), Toward Justice: Broadening the Study of Criminal Justice. New York: Routledge.

Johnson, B. D. (1998), "The Cybernetics of Society: The Governance of Self and Civilization." Jurlandia.

Kaplan, F. (2017), Dark Territory: The Secret History of Cyber War. Reprint, London: Simon $\&$ Schuster.

Kasper, A. and Antonov A. (2019), "Towards Conceptualizing EU Cybersecurity Law." ZEI Discussion Paper C 253/2019. Bonn, Germany: Center for European Integration Studies, Universität Bonn.

Kikerpill, K. and Siibak A. (2019), 'Living in a Spamster's Paradise: Deceit and Threats in Phishing Emails", Masaryk University Journal of Law and Technology, Vol. 13 No. 1, pp. 4566.

Kline, R. R. (2006), "Cybernetics, Management Science, and Technology Policy: The Emergence of 'Information Technology' as a Keyword, 1948-1985”, Technology and Culture, Vol. 47 No. 3, pp. 513-535.

Kline, R. R. (2015), The Cybernetics Moment: Or Why We Call Our Age the Information Age. Baltimore: Johns Hopkins University Press.

Laclau, E. (1994), “Why Do Empty Signifiers Matter to Politics?”, in Weeks J. (Ed) The Lesser Evil and the Greater Good: The Theory and Politics of Social Diversity, London: Rivers Oram Press.

Lafrance, A. (2015), "When People Feared Computers", The Atlantic, March 30, available at: https://www.theatlantic.com/technology/archive/2015/03/when-people-fearedcomputers/388919/ (accessed 23 February 2021)

Lillemose, J. and Kryger, M. (2015), "The (Re)invention of Cyberspace", Nordic Art Review, August 24, available at: https://kunstkritikk.com/the-reinvention-of-cyberspace/ (accessed 23 February 2021)

Lundgren, B. and Möller, N. (2019), "Defining Information Security", Science and Engineering Ethics, Vol. 25 No. 2, pp. 419-441. https://doi.org/10.1007/s11948-017-9992-1

MacKillop, E. (2018), "How Do Empty Signifiers Lose Credibility? The Case of Commissioning in English Local Government”, Critical Policy Studies, Vol. 12 No. 2, pp. 187208. DOI:10.1080/19460171.2016.1236740

Maimon, D. and Louderback E. R. (2019), "Cyber-dependent Crimes: An Interdisciplinary Review”, Annual Review of Criminology, Vol. 2 No. 16, pp. 191-216. 10.1146/annurevcriminol-032317-092057

McGuire, M. and Dowling S. (2013), Cybercrime: A Review of the Evidence: Summary of Key Findings and Implications. Research Report, 75. London: Home Office. 
Mehlmann, J. (1972), “The 'Floating Signifier': From Lévi-Strauss to Lacan”, Yale French Studies, Vol. 48, pp. 10-37.

Naughton, J. (2016), “The Evolution of the Internet: From Military Experiment to General Purpose Technology", Journal of Cyber Policy, Vol. 1 No. 1, pp. 5-28. https://doi.org/10.1080/23738871.2016.1157619

Newitz, A. (2013), "The Bizarre Evolution of the Word 'Cyber"”, Gizmodo, September 13, available at: https://io9.gizmodo.com/today-cyber-means-war-but-back-in-the-1990s-it-mean1325671487 (accessed 23 February 2021)

Nolan, C., Lawyer G. and Dodd R. M. (2019), “Cybersecurity: Today's Most Pressing Governance Issue.” Journal of Cyber Policy. DOI:10.1080/23738871.2019.1673458

Novikov, D. A. (2016), Cybernetics: From Past to Future. Springer International Publishing.

Perlroth, N. (2013), “Luring Young Web Warriors Is Priority. It's Also a Game”, New York Times, March 24, available at: https://www.nytimes.com/2013/03/25/technology/united-stateswants-to-attract-hackers-to-public-sector.html (accessed 23 February 2021)

President's Commission on Critical Infrastructure Protection. (1997), Critical Foundations: Protecting America's Infrastructures. Washington, D.C.

Rid, T. (2016), Rise of the Machines: A Cybernetic History. New York: W. W. Norton \& Company.

Sarre, R., Lau L Y-C. and Chang L. Y. C. (2018), "Responding to Cybercrime: Current Trends", Police Practice and Research, Vol. 19 No. 6, pp. 515-518. https://doi.org/10.1080/15614263.2018.1507888

Schallbruch, M. and Skierka I. (2018), Cybersecurity in Germany. Springer International Publishing.

Schatzberg, E. (2006), “'Technik' Comes to America: Changing Meanings of 'Technology' Before 1930", Technology and Culture, Vol. 47 No. 3, pp. 486-512.

Scott, K. (2018), "A Second Amendment for Cyber? - Possession, Prohibition and Personal Liberty for the Information Age", in Jøsang A. (Ed) Proceedings of the 17th European Conference on Cyber Warfare and Security, Oslo, pp. 464-470.

Tabansky, L. and Israel I. B. (2015), Cybersecurity in Israel. Cham: Springer.

Tikk-Ringas, E. (2015), Evolution of the Cyber Domain: The Implications for National and Global Security. New York: Routledge.

Time. (1965), “Technology: The Cybernated Generation”, April 2.

Time. (1982), “The Computer Moves In”, December 26.

Von Solms, R. and Niekerk J. v. (2013), "From Information Security to Cyber Security", Computers \& Security, Vol. 38, pp. 97-102. https://doi.org/10.1016/j.cose.2013.04.004

Warner, M. (2012), “Cybersecurity: A Pre-History", Intelligence and National Security, Vol. 27 No. 5, pp. 781-799. https://doi.org/10.1080/02684527.2012.708530 
Wiener, N. (1948), Cybernetics or Control and Communication in the Animal and the Machine. Cambridge, MA: The MIT Press.

Wiener, N. (1956), I Am a Mathematician: The Later Life of a Prodigy. New York: Doubleday.

Wiener, N. (1964), God and Golem, Inc.: A Comment on Certain Points where Cybernetics Impinges on Religion. Cambridge, MA: MIT Press.

Wolchover, N. (2015), “This Artificial Intelligence Pioneer Has a Few Concerns”, Wired, May 23, available at: https://www.wired.com/2015/05/artificial-intelligence-pioneer-concerns/ (accessed 23 February 2021)

Wolff, J. (2016), "Cyber is Not a Noun", Slate, September 9, available at: https://slate.com/technology/2016/09/cyber-is-not-a-noun.html (accessed 23 February 2021)

Zimmerman, K. A. (2017), "History of Computers: A Brief Timeline", LiveScience, September 7, available at: https://www.livescience.com/20718-computer-history.html (accessed 23 February 2021) 